\title{
What Do Freshmen Know about Sustainability? Analysing the Skill Gap among University Business Administration Students
}

\author{
Alba Manresa ${ }^{1, *(\mathbb{C}}$, Jasmina Berbegal-Mirabent ${ }^{1}\left(\mathbb{D}\right.$, Úrsula Faura-Martínez $^{2}{ }^{(\mathbb{C}}$ and Juan-Vicente Llinares-Ciscar ${ }^{2} \mathbb{(}$ \\ 1 Faculty of Economics and Social Sciences, Universitat Internacional de Catalunya, 08017 Barcelona, Spain; \\ jberbegal@uic.es \\ 2 Faculty of Economics and Business, Universidad de Murcia, 30100 Murcia, Spain; faura@um.es (Ú.F.-M.); \\ llinares@um.es (J.-V.L.-C.) \\ * Correspondence: amanresa@uic.es
}

Citation: Manresa, A.; Berbegal-Mirabent, J.; Faura-Martínez, Ú.; Llinares-Ciscar, J.-V. What Do Freshmen Know about Sustainability? Analysing the Skill Gap among University Business

Administration Students.

Sustainability 2021, 13, 8813. https:// doi.org/10.3390/su13168813

Academic Editors:

Fermin Sanchez-Carracedo,

Jordi Segalàs Coral and

Gemma Tejedor

Received: 25 June 2021

Accepted: 3 August 2021

Published: 6 August 2021

Publisher's Note: MDPI stays neutral with regard to jurisdictional claims in published maps and institutional affiliations.

Copyright: (c) 2021 by the authors. Licensee MDPI, Basel, Switzerland. This article is an open access article distributed under the terms and conditions of the Creative Commons Attribution (CC BY) license (https:// creativecommons.org/licenses/by/ $4.0 /)$.

\begin{abstract}
This study aims at creating and validating an instrument to assess the level of mastery in sustainability competencies of freshmen students in business-related studies. To reach this goal, a questionnaire that captures the level of acquisition of the competencies in sustainability is provided. A three-step process has been followed to analyse the results gathered among first-year students in two Spanish universities. First, eight confirmatory factor analyses were conducted to verify the grouping of the dimensions included in the questionnaire, resulting in 10 competency units in sustainability (CU). Next, we averaged the values of the items included in each CU to facilitate interpretation and then calculated the skill gap; that is, the difference between the level that CU students are expected to achieve on graduation compared to the current level. Third, a series of ANOVA tests were run to investigate potential differences in the level of acquisition due to gender, prior training and educational background, which according to the literature might influence current student knowledge of sustainability. Our results reveal that freshmen enter university with a heterogeneous level of development, both in terms of breadth (different CUs) and depth (the extent to which each CU is developed). The original value of this work stems from the creation of an instrument which is expected to be applicable in a variety of contexts. Additionally, the information it provides assists us in the identification of the CUs that should be further emphasized at university level, and therefore helps professors to prioritise those teaching strategies targeted at overcoming this deficit.
\end{abstract}

Keywords: higher education; curriculum for sustainability; sustainability competencies; business and administration; skill gap

\section{Introduction}

Nowadays, no one questions the emergency planetary situation in which we find ourselves: global warming of the atmosphere, depletion of the stratospheric ozone layer, deforestation, loss of biodiversity, unlimited growth with hyper-consumption in the face of extreme poverty and overpopulation in cities, etc. [1-3]. Resources are limited and humans are depleting the Earth's natural capital at a dizzying rate.

In the 1980s, the concept of sustainability and sustainable development emerged to highlight the situation and solve the difficulties facing the world today, which seriously threaten our future. Various international organisations and bilateral and multilateral agencies such as Official Development Assistance (ODA), the Organisation for Economic Cooperation and Development (OECD), the United Nations Educational, Scientific and Cultural Organisation (UNESCO) and the United Nations, among others, have sought and are seeking measures to alleviate these problems. These actions range from international cooperation for guiding policies towards making the changes required to improve sustainability, to actions for increasing the levels of awareness and commitment of indi- 
viduals, businesses, institutions and governments. The measures proposed by experts in order to make the world more sustainable can be grouped into three clusters [4]:

- $\quad$ scientific-technological (for instance, developing clean energies and increasing process efficiency), leading towards a circular economy.

- educational, aimed at changing attitudes and behaviour (such as responsible consumption, fair trade and citizen activism).

- political (likewise legislation for environmental protection, at a local and global level, and binding agreements for the eradication of extreme poverty).

The European Higher Education Area focuses training on student learning and learning outcomes measured by means of competencies [5]. Future professionals can be trained in competencies by promoting social transformation through a sustainability approach. It is therefore essential to include sustainability training in university studies (also at any level of formal-early childhood, primary and secondary- and informal education). Education linked to real problems must be provided in order to produce professionals with skills in critical thinking, active learning, collaborative work and emotional intelligence, among other skills required to tackle current problems and those in the future of society [6-8].

Higher education institutions constitute a fundamental means of implementing these types of measures and to ensure their impact on society $[9,10]$. To this end, it is essential to have the following information:

- Knowing what kind of sustainability competencies our students should acquire so that they can become agents of change, able from the professional field in which they are engaged to transmit to society the values and guidelines reflected in the 2030 Agenda and the SDGs [11]. The competencies in sustainability will provide a response to the social, economic and environmental issues, both global and local, facing our interrelated societies.

- Once the competencies that should be developed have been defined, determine the extent to which they have been acquired and perceived by the students. This information will be highly valuable for the design of academic programmes that enhance those competencies in which students are most lacking.

Given that students in the field of business administration and management will be the future decision-makers in the sphere of production and consumption, it is essential that they are fully prepared in education for sustainable development. In their jobs, they will act as drivers of change in order to raise awareness and modify individual and social behaviour to make it more sustainable. It is therefore very important to determine the degree of knowledge they possess about sustainability so that more precise and effective approaches can be made towards their training.

In order to provide new evidence on this matter, the present study proposes a questionnaire aimed at capturing the level of students' self-perception regarding proficiency in sustainability competencies when undertaking the Bachelor's Degree in Business Administration and Management (GADE). Second, we validate this instrument by conducting an empirical analysis among first year GADE students enrolled at the Universidad de Murcia and the Universitat Internacional de Catalunya (both universities located in Spain). With the information collected we calculate the skill gap; that is, the difference between the expected level they should possess when graduating and their current level of acquisition (at the time of entry) of sustainable competencies. The results obtained are expected to help academics reformulate the teaching strategies used at undergraduate level in order to ensure full acquisition of sustainable competences at the time of graduation. Likewise, the results might also be valuable at lower educational levels, helping teachers to reconsider the pedagogical strategies that might help decrease a potential skill gap between college and university. 
Taking into account the above-mentioned considerations, this paper contributes to the existing literature by providing an explicit response to the following research questions:

RQ1: What is the students' self-perception of their level of acquisition of sustainability competencies before entering university?

RQ2: What is the skill of the different sustainability competencies?

After this introduction, the rest of the article is structured as follows. First by the conceptual frame of reference, which presents the literature review regarding sustainability in higher education as well as works focusing on the specific field of business administration and management. Section 3 explains the methodology employed, with a description of the instrument used for the analysis of sustainability knowledge as well as its application in a specific context (Universidad de Murcia and Universitat Internacional de Catalunya) and the type of analysis carried out with the data collected. The results are presented in Section 4, while their interpretation and implications are described in Section 5, together with a summary of the main contributions and an outline of future lines of research.

\section{Theoretical Background}

\subsection{Relevance of Sustainability in Higher Education}

Education is an important element in addressing today's challenges [7,12,13]. The need to mainstream sustainable development at all levels of education has been explicitly mentioned in three world summits on sustainable development: the United Nations Conference on Environment and Development in Rio de Janeiro (1992), the World Summit on Sustainable Development in Johannesburg (2002) and the United Nations Conference on Sustainable Development in Rio de Janeiro (2012). It has also been included in other agreements such as the UN Decade of Education for Sustainable Development (2005-2014) or the Global Action Programme on Education for Sustainable Development.

More recently, it has been addressed in the 2030 Agenda for Sustainable Development [14] in the belief that sustainability should be an indispensable element of quality education. It is a "a universal call to action to end poverty, protect the planet and improve the lives and prospects of everyone, everywhere" [15]. In this agenda, 17 Sustainable Development Goals (SDGs) were established with a specific goal on education (number 4) and related targets in 7 of the 17 SDGs. Goal 4 is formulated in the following terms: "Ensure inclusive and equitable quality education and promote lifelong learning opportunities for all" by 2030 [16] (p. 3). Specifically, it includes Target 4.7, which is directly related to Education for Sustainable Development: "By 2030, ensure that all learners acquire the knowledge and skills needed to promote sustainable development, including, among others, through education for sustainable development and sustainable lifestyles, human rights, gender equality, promotion of a culture of peace and non-violence, global citizenship and appreciation of cultural diversity and of culture's contribution to sustainable development" [14] (p. 17).

Sustainability includes several areas $[17,18]$ : social (such as family, education and future generations), economic (likewise fair trade and finance) and environmental (for instance, reduction in $\mathrm{CO}_{2}$ emissions and pollution). Of these, the social sphere has received the least attention (Juárez-Hernández et al., 2019). People should be educated with a holistic vision that includes the social, economic and environmental components (the aim is to raise critical issues related to the environment and development, and to formulate realistic proposals to address them). The report "Growth without economic growth" produced by the European Environment Agency [19], shows the relationship between economic growth and certain indicators of human well-being such as education.

This context calls for a re-examination of academic curricula at all levels (from preschool to higher education) and their adaptation to these new requirements. It is clear that teaching about the environment, the economy, or citizenship without basic knowledge is difficult, but it is also true that it is not enough just to increase basic knowledge about the environment, the economy and society. It is also about enhancing students' learning of the skills, perspectives and values that guide and motivate them to seek more sustainable ways of earning a living, participating in a democratic society, improving the quality of life 
and living in a sustainable way. These issues, values, perspectives, skills and knowledge for addressing sustainability need to be included in educational programmes [20].

Universities have a very important role to play in improving the sustainability of the planet. The young people who receive their education in these institutions will be the future leaders of society; they will lead all sectors (government, legislation, business, communication and education); they will have to make decisions in a world struggling to achieve sustainability. An education aligned with these values will enable them to acquire new competencies, thereby forging responsible citizens who contribute to sustainable social development. Universities must prepare them so that through their actions and collaborative work they will be capable of contributing to the sustainable development of companies, the strengthening of the economy, the improvement of coexistence, inclusion, care for the environment, etc. [14,21-24].

Spanish universities are working along the lines set out by the 2030 Agenda, as shown in a survey conducted by the Conference of Rectors of Spanish Universities at the beginning of 2018 [25]. This survey reveals that $67 \%$ of the 76 universities have already implemented action mechanisms in pursuit of this aim. Among the various projects promoted by universities in response to these new training needs, the EDINSOST project in particular (Education and Social Innovation for Sustainability), funded by the Spanish Ministry of Economy, Industry and Competitiveness within the framework of the R\&D\&I Research Challenges programme, merits attention. This project started in 2016 with the collaboration of ten Spanish universities (Universidad Autónoma de Madrid, Universidad de Córdoba, Universitat de Girona, Universidad de Cádiz, Universidad Camilo José Cela, Universidad Internacional de Cataluña, Universitat Politècnica de Catalunya, Universidad de Sevilla, Universidad de Salamanca and Universidad Politécnica de Madrid) with the aim of studying how sustainability competencies should be integrated into the different degrees of the Spanish University System. The project came to an end in 2019 and gave rise to EDISNSOST2, which goes a step further by analysing the implementation of sustainability in 15 degrees in the fields of education, engineering and business. EDISNSOST2 seeks to achieve four specific objectives:

- $\quad$ Objective 1 (O1): To define a Sustainability Competency Map for each participating degree and the creation of a common framework for introducing the maps into the degrees in a holistic way;

- $\quad$ Objective $2(\mathrm{O} 2)$ : To validate different didactic strategies for addressing sustainability through a constructivist and community pedagogical approach;

- Objective 3 (O3): To diagnose the status of the training needs of the teachers in each degree concerning sustainability, as well as to develop and test training proposals;

- Objective $4(\mathrm{O} 4)$ : To diagnose the sustainability competency level of current university students and to develop training proposals.

This study contains the results of the first part of O4. Specifically, it describes the instrument designed to assess students' level of acquisition of sustainability competencies on leaving college and just prior to undertaking higher education studies, and particularize this instrument for students in business administration. Furthermore, this objective (as well this paper) includes the description of the methods used to analyse the responses obtained as a result of distributing the instrument among first-year students.

\subsection{Sustainability in Business Administration and Management Studies}

For some years now, the circular economy, the green economy, the theory of degrowth and post-growth, among many others, have been promoted with the aim of maintaining the added value of products for as long as possible by reducing waste to minimum levels [26]. The future lies in replacing the linear economy, based only on consumption, with a circular economy, focused on the reuse of the resources present in waste. A circular economy can be defined as an economic model aimed at the efficient use of resources through waste minimisation, long-term value retention, reduction in primary resources, closed loops of products, product parts and materials within the boundaries of environmental 
protection and socioeconomic benefits [27]. In other words, the circular economy seeks to develop a sustainable economic model aimed at improving social welfare by implementing environmentally friendly and socially committed enterprises. It will thereby contribute to reducing poverty and guaranteeing quality development for present and future generations, without compromising the planet's resources.

In order to achieve a sustainable world, the economy must be placed at the service of society in order to provide solutions to current problems such as fair food distribution, reduction in the use of fossil fuels, eradication of poverty, etc. In this transition towards a green model, the role of citizens is fundamental. Hence, the importance of training all graduates in sustainability, especially students in business-related disciplines, such as those enrolled in GADE, since these students are the ones who in the future will make decisions on production (use of resources, choice of processes and technologies, distribution, among others). Students should possess a holistic vision, be aware of the impact of economic, social and environmental decisions and learn methodologies to apply the sustainability and circularity of the economy in real situations. GADE graduates should know and understand the complexity of society and the relationships between the economic agents involved in order to be able to promote and propose solutions to problems related to sustainable development that arise in their workplaces. Graduates in this profile should be aware that the decisions they make in their future professional positions have consequences not only in the short term and in their work environment, but also in the long term and in other sectors, generating externalities that could be positive or negative [28].

In order to design teaching-learning strategies that enable the development of these competencies, it is first of all necessary to analyse the level of proficiency of incoming students when they arrive at university. This level is likely to vary greatly between one student and another, given that the inclusion of these concepts in the educational levels prior to university can be highly heterogeneous. There are several studies that analyse the level of integration of the concept of sustainable development in primary and secondary school. Michalos et al. $[29,30]$ analyse attitudes, knowledge and behaviour towards sustainable development in Canada. They conclude that students who have better attitudes towards sustainability are those who are more knowledgeable about sustainability, although the correlation between attitude and favourable behaviour towards sustainability is low. Olsson et al. (2015) [31] and Boeve-de Pauw et al. (2015) [32] analyse how the study of the SDGs can influence the sustainability knowledge of primary school pupils in Sweden. Their results indicate that sixth graders in schools where education for sustainable development is implemented in the curriculum are more aware of sustainability issues, although for ninth graders the effect was negative. Suárez-López and Marcia EugenioGozalbo (2021) [33] analyse the sustainability content in the curricula of primary and secondary school pupils in Spain and Portugal, and find that there is a limited presence of sustainability-related content, as well as deficiencies in the inclusion of the social and economic dimensions of the concept of sustainability.

Previous studies lead us to believe that students arrive at university with a varying knowledge of sustainability competencies, depending on the school and the branch of knowledge of previous studies [34]. Cultural and family background may also play an important role $[35,36]$. Likewise, as noted by $[37,38]$ these differences may also be due to gender, since women tend to have a higher predisposition to developing sustainability competencies.

This heterogeneity poses a challenge for universities when it comes to promoting the development of sustainability competencies, which justifies the need for an instrument to enable a diagnosis of what the starting situation may be, in order to subsequently make more targeted training decisions, both in terms of focus and personalization, according to the shortcomings detected. To the best of the authors' knowledge, no current study yet exists that analyses the knowledge of first-year students in business administration and management degrees. There are, however, studies on other degrees involved in the EDINSOST project and for university students in higher years. Thus, Sánchez-Carracedo et al. 
(2021) [39] analyse the extent to which sustainability is present in the curricula of some education degrees; Valderrama-Hernandez et al. (2020) [40] base their study on focus groups of fourth-year students from four universities; Sánchez-Carracedo et al. (2021) [41] focus on first- and fourth-year students from several education degrees; and Sánchez-Carracedo et al. (2019) [42] focus on the curricula of engineering degrees.

\section{Methodology}

\subsection{Context of the Study}

In order to design the questionnaire that helps us determine the level of sustainability competencies of GADE students, the competency map developed for each of the degrees forming part of the EDINSOST project $[11,43]$ was used as a starting point. The structure of the competency map was based on four competencies related to sustainability as defined by the Sectorial Commission CRUE-Sustainability [25]:

- C1: Critical contextualization of knowledge establishing interrelationships with local and/or global social, economic and environmental problems;

- C2: Sustainable use of resources and prevention of negative impacts on the natural and social environment;

- C3: Participation in community processes that promote sustainability;

- C4: Application of ethical principles related to the values of sustainability in personal and professional behaviour.

Each competency was studied from the holistic perspective, except for C2, which was also analysed taking into account the three dimensions of sustainability (i.e., social, environmental, and economic). For each dimension, one or more competency units were defined. The learning outcomes for each competency unit were defined using a simplified version of the Miller pyramid as a taxonomy: (1) knowing, (2) knowing how, (3) demonstrating and doing. The sustainability maps developed in EDINSOST for the different degrees involved in the study can be found in Sánchez-Carracedo et al. [42,44]. Table 1 reports the association between competencies and units of competencies.

Although all four maps share a common baseline, each map has been particularised according to the discipline. For the purpose of this paper, we concentrate on the competency map for business administration graduates (three additional competency maps exist in the fields of engineering, environmental sciences and education, as detailed in Segalàs and Sánchez-Carrecedo (2019) [11]). This map emerges as an effective instrument for monitoring students' progress in the level of acquisition of the learning outcomes linked to the different sustainability competencies. It is expected that at the time of graduation a student should have developed all the competencies listed therein.

Table 1. Association between competencies, competency units and items included in the questionnaire (by competency unit).

\begin{tabular}{|c|c|c|c|}
\hline Competence & Competency Unit and Description & Id & Operationalization \\
\hline \multirow{7}{*}{$\mathrm{C} 1$} & \multirow{3}{*}{ CU1. General knowledge } & CU1_a & $\begin{array}{l}\text { I am familiar with the concepts of sustainability } \\
\text { and sustainable development }\end{array}$ \\
\hline & & CU1_b & $\begin{array}{l}\text { I am aware of different economic approaches that } \\
\text { promote sustainable development. }\end{array}$ \\
\hline & & CU1_c & $\begin{array}{l}\text { I am aware of the roles, rights and duties of the } \\
\text { different stakeholders }\end{array}$ \\
\hline & \multirow{4}{*}{$\begin{array}{l}\text { CU2. Sustainable dimensions (social, economic and/or } \\
\text { environmental problems) of today's society, both locally } \\
\text { and globally }\end{array}$} & CU2_a & $\begin{array}{c}\text { I am aware of the principal causes, consequences } \\
\text { and agents that are part of the problems related } \\
\text { to the sustainable dimensions }\end{array}$ \\
\hline & & CU2_b & $\begin{array}{l}\text { I am aware of some international initiatives to } \\
\text { reduce sustainable problems }\end{array}$ \\
\hline & & CU2_c & $\begin{array}{l}\text { I am able to critically reflect on the different } \\
\text { dimensions of sustainability in the analysis of a } \\
\text { situation related to my professional field }\end{array}$ \\
\hline & & CU2_d & $\begin{array}{l}\text { I am able to relate a sustainability problem to the } \\
\text { methods and strategies used to address them. }\end{array}$ \\
\hline
\end{tabular}


Table 1. Cont.

\begin{tabular}{cc}
\hline Competence & Competency Unit and Description \\
\hline & \\
& $\begin{array}{c}\text { CU3. Environmental impact of products and services } \\
\text { related to my professional field (e.g., environmental } \\
\text { footprint, pollutant emissions, resource/energy } \\
\text { consumption, environmental impact matrix, impact on } \\
\text { biodiversity, waste generation) }\end{array}$
\end{tabular}
biodiversity, waste generation)

Id Operationalization

CU3_a

CU3_b

CU3_c

CU3_e

I know metrics (or tools) to measure environmental impact

I am aware of strategies or technologies to reduce, reuse and recycle resources and waste

I am aware of the environmental impact of products and services related to my professional field throughout their life cycle (extraction, production, use and end-of-life)

I can use appropriate metrics (or tools) to measure environmental impact

In my professional field, I try to contribute to the improvement of the environment, taking into account environmental criteria and including indicators to measure the environmental impact

\section{$\mathrm{C} 2$}

\begin{tabular}{cc}
\hline & CU4_j. Social justice implications of \\
projects and actions in my professional \\
field (e.g., equity, diversity, common \\
good, transparency, human rights, \\
gender perspective, needs of the most \\
vulnerable groups, discrimination, \\
dignity, anti-corruption)
\end{tabular}

CU5_v. Methods and tools to estimate the economic viability of a project (e.g., externalities analysis, CANVAS analysis, SWOT analysis, business plan, strategic

CU5. plan, cost-benefit, etc.)

Economic feasibility and resources management

CU5_g. Management of resources (material, economic and human) applicable to project management
CU4_j_a I know the basic concepts of social justice related to my professional field.

CU4_j_b I understand the social justice implications of products and services in my professional field.

CU4_j_c I take social justice criteria into account in projects and actions in my professional field.

I know metrics (or tools) that measure and describe the CU4_i_a social impact of products and services related to my professional field

I know how to use metrics (or tools) to measure the
CU4_i_b social impact of products and services related to my professional field.

CU4_i_c I include indicators to measure the social impact of projects in my professional field.

CU5_v_a I know methods (or tools) to estimate the economic viability of a project

CU5_v_b I am able to understand the economic feasibility plan of a project or service in my professional field

CU5_v_c I am able to draw up an economic feasibility plan for a project in my professional field.

I can critically assess whether the economic viability of

CU5_v_d my project is compatible with the environmental and social aspects of sustainability.

CU5_g_a I know the basics concepts (e.g., fixed and variable

costs, depreciation, budgets, Gantt charts, etc.).
CU5_g_b I know how to interpret the economic feasibility plan of a project.

I know how to analyse real cases of project or service

CU5_g_c management and identify the economic consequences for society.

CU5_g_d I am able to plan a project and to follow the economic follow-up in all its phases.

I am aware of the strategic role of my profession in sustainability and the direct and indirect consequences

CU6_a sustainability and the direct and indirect consequences
of the use of products and services in my professional
field on society, the economy and the environment.

CU6_a $\begin{gathered}\text { sustainability and the direct and indirect consequence } \\ \text { of the use of products and services in my professional } \\ \text { field on society, the economy and the environment. }\end{gathered}$

CU6_b I can analyse alternatives to decide which is the most sustainable and to what extent it solves the problem

CU6_c I know how to apply sustainability approaches in production, consumption and recycling.

CU6. Projects, products and services related to my professional field of expertise

CU6_d

I am able to monitor a project for sustainability, and to select which indicators will be used to measure sustainability.

I am able to propose sustainable projects in my professional field, or to come up with new ideas and

CU6_e solutions to make projects more sustainable, taking into account environmental, economic and social aspects 
Table 1. Cont.

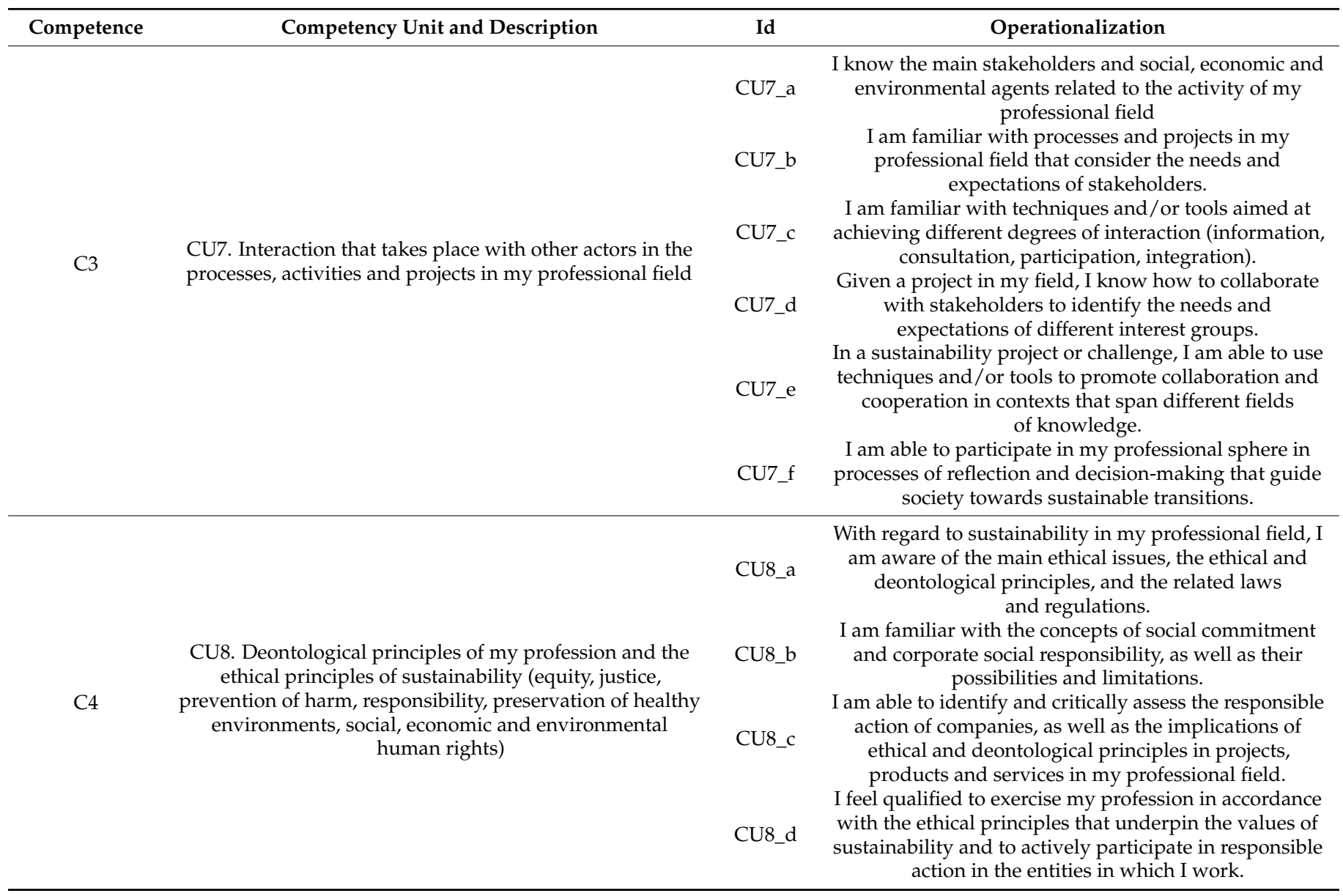

\subsection{The Survey}

A questionnaire was designed on the basis of the competency map. The purpose of this instrument is to capture freshmen students' level of acquisition of the different competencies in sustainability (as listed in Table 1). To do so, we first embarked on a conceptual revision of the different concepts related to each competency. At this stage, we also looked for previous academic articles devoted to gathering students' perceptions about sustainability and its associated skills. After collecting and revising the relevant information, we concluded that the questionnaire we had in mind should focus on the sustainability competency itself, rather than on the habits each of them entail. In accordance with this approach, an initial version of the questionnaire was drafted using as key pillars the units of competency of the sustainability map. A series of items were proposed for each competency unit.

Once an initial version of the questionnaire was ready, two rounds of review were conducted. Particularly, we validated the suitability of the structure and items in the questionnaire in two main ways. First, we shared and discussed the instrument with the other members working on the O4 work package in the EDINSOST project. Second, we extended the invitation to all the members of the EDINSOST project, who have a solid experience in the field (development of sustainable competencies). Based on the comments received, the instrument was updated and a revised version was obtained. An online version was then created using Google forms as the platform to distribute and collect the responses. 
In order to ensure that all the questions were clearly stated and there was no room for misinterpretations, a group of 10 experts in sustainability-external to the project-was contacted. They were asked to provide feedback of the online version of the questionnaire, as well as to assess the relevance of each question and the readability of the statements in the questionnaire. Additionally, a pilot test was conducted with a group of 20 students enrolled in GADE at both the Universidad de Murcia and the Universitat Internacional de Catalunya (the target population of the EDINSOST2 project). Students were asked to fill in the questionnaire. Afterwards, a focus group was organized in order to gather students' perceptions about the ease of response to the questionnaire (clarity of the writing), their impressions when answering it (too difficult or easy) and the time it took to complete it. Minor changes were introduced as a result of this final double-check.

The final version of the questionnaire includes a total of 41 questions, comprising items that relate to the eight competency units (from CU1 to CU8). Table 1 reports the association between competencies and competency units and the items included in the questionnaire (by competency unit). For each of these questions, students should indicate their level of agreement in a 4-point Likert scale (from strongly disagree to strongly agree). The questionnaire also contained an initial section in which we collected information about characteristics of the respondents that according to the literature might influence the level of acquisition of sustainability competencies: gender, age, university in which they are enrolled, prior training in sustainability, and field of the degree of entry (science and technology, humanities and social sciences, arts, others).

\subsection{Sample}

The students that responded to the questionnaire were first-year students enrolled in the GADE at the Universidad de Murcia (UM) and the Universitat Internacional de Catalunya (UIC). These two universities participate in the EDINSOST2 project and are responsible for the study of the competencies on sustainability in the business and administration degree. An invitation to participate was sent in November 2020 by email to all freshmen students, explaining the purpose of the project and the link to the questionnaire. A total of 143 answers were collected (88 from UM and 55 from UIC). After removing invalid responses (surveys that were returned containing missing values), the final dataset consists of 133 valid responses ( 81 from UM and 52 from UIC).

\subsection{Control Variables}

As mentioned in Section 3.2, the questionnaire included a series of items (considered here as control variables) aimed at capturing the profile of the students which, according to the literature, might explain potential differences in the level of acquisition of sustainability competencies. These are as follows: field of the degree of entry (field), gender (gender), and training in sustainability prior to university entry (training). We also collected information concerning the university in which they are enrolled (HEI), and students' age (age).

Table 2 shows the distribution of students (by university and total) based on their fields of study. In Spain, three main fields can be distinguished: arts, science and technology, humanities and social sciences. Despite this variety, it is commonly found that students who wish to pursue a business-related degree complete their previous studies in the areas of humanities and social sciences. Therefore, it is not surprising that almost $75 \%$ of the students surveyed came from this domain. Consequently, for further analysis, we distinguish between students coming from social sciences and humanities, and those from other fields (coded as 1 and 0, respectively). 
Table 2. Descriptive analyses by field of studies prior to university entry.

\begin{tabular}{cccc}
\hline Field of the Degree of Entry & UM $(\mathbf{N}=\mathbf{8 1})$ & UIC $\mathbf{( N ~ = ~ 5 2 ) ~}$ & TOTAL (N = 133) \\
\hline Arts & 0 & 0 & 0 \\
Science and technology & $19.75 \%$ & $23.08 \%$ & $21.05 \%$ \\
Social sciences and humanities & $77.78 \%$ & $69.23 \%$ & $74.44 \%$ \\
Others & $2.47 \%$ & $7.69 \%$ & $4.51 \%$ \\
Total & $100.00 \%$ & $100.00 \%$ & $100.00 \%$ \\
\hline
\end{tabular}

The descriptive statistics for the control variables are reported in Table 3. The distribution of both subsamples (UIC and UM) is quite similar. The main differences refer to the variable training, in which UIC students seem to be the most outstanding, with approximately $62 \%$ of the students having received previous training in sustainability prior to entering the university. This percentage is significantly smaller among UM students $(30 \%)$. Concerning the other variables, students are gender-balanced, with $46 \%$ of the total sample being female (the percentage is slightly higher in UM).

Table 3. Descriptive statistics of the control variables by university.

\begin{tabular}{cccccc}
\hline HEI & Statistic & Age & Gender & Studies & Training \\
\hline \multirow{4}{*}{ UM } & Mean & 18.75 & 0.481 & 0.778 & 0.296 \\
& St. Dev. & 1.912 & 0.503 & 0.418 & 0.459 \\
& Max & 29 & 1 & 1 & 1 \\
& Min & 17 & 0 & 0 & 0 \\
\hline \multirow{3}{*}{ UIC } & Mean & 18.153 & 0.423 & 0.792 & 0.615 \\
& St. Dev. & 0.777 & 0.499 & 0.466 & 0.491 \\
& Max & 21 & 1 & 1 & 1 \\
& Min & 17 & 0 & 0 & 0 \\
\hline \multirow{3}{*}{ TOTAL } & Mean & 18.515 & 0.459 & 0.744 & 0.421 \\
& St. Dev. & 1.59 & 0.500 & 0.437 & 0.500 \\
& Max & 29 & 1 & 1 & 1 \\
& Min & 17 & 0 & 0 & 0 \\
\hline
\end{tabular}

For further analysis, the above percentages suggest that it is not necessary to work independently with the two subsamples (UM and UIC), but rather to consider all the observations together. Another argument that supports this decision is that, since we are interested in determining the extent to which freshmen have developed the competencies in sustainability before starting higher education, the university in which they are currently enrolled is irrelevant insofar as it has not yet been able to have any effect on the students knowledge. Thus, discrimination by university may lead to erroneous conclusions. These data reveal that, while it appears that differences in the level of proficiency of sustainability competencies between UIC and UM students exist, these possible differences can be explained by other factors (as noted above in the literature review section).

\subsection{Method}

A three-step analysis was proposed to analyse the data. First, eight confirmatory factor analyses were conducted (using principal component analysis) to verify the grouping of the dimensions among the items of sustainable competencies included in the questionnaire. The results (see Table 4) confirmed the unidimensionality of all competency units (internal consistency of the factors), with the exception of CU4 and CU5, which were better captured if the competency unit was split into two, according to the division that emerged from the discussion with the members of the EDINSOST project when designing the survey. In order to facilitate the analysis and interpretation of the scores obtained in each $\mathrm{CU}$, and to determine the existence of any skill gap or potential differences by control variables, an alternative approach was used to calculate the resulting factor for each CU. Specifically, 
we averaged the values of the items included in each $\mathrm{CU}$, thereby retaining the scale metric, which may facilitate comparisons across CUs. In addition, this method makes it easier to explain the results by weighing the response of each item with its relevance to the explanation [37]. We compared the results between the two approaches (principal component analyses and the simple average of the scores) and found that the results presented no significant differences. Therefore, this latter approach is adopted in the results presented in the following sections.

Table 4. Loads of the confirmatory factor analysis.

\begin{tabular}{|c|c|c|c|c|c|}
\hline & $\begin{array}{l}\text { Factor } \\
\text { Loading }\end{array}$ & $\begin{array}{c}\text { Cronbach's } \\
\text { Alpha }\end{array}$ & & $\begin{array}{c}\text { Factor } \\
\text { Loading }\end{array}$ & $\begin{array}{c}\text { Cronbach's } \\
\text { Alpha }\end{array}$ \\
\hline CU1 & $\begin{array}{c}0.5210 \\
0.6187 \\
0.588\end{array}$ & 0.5987 & \multirow[t]{2}{*}{ CU5v } & $\begin{array}{l}0.3574 \\
0.3574 \\
0.3356\end{array}$ & \multirow[t]{2}{*}{0.8389} \\
\hline & 0.5560 & & & 0.3524 & \\
\hline CU2 & $\begin{array}{l}0.5183 \\
0.5187 \\
0.4017\end{array}$ & 0.6471 & \multirow[t]{2}{*}{ CU5g } & $\begin{array}{l}0.3601 \\
0.3684 \\
0.3234\end{array}$ & \multirow[t]{2}{*}{0.8712} \\
\hline & 0.2922 & & & 0.3712 & \\
\hline CU3 & $\begin{array}{l}0.4693 \\
0.5123 \\
0.3938 \\
0.5261\end{array}$ & 0.6849 & \multirow[t]{2}{*}{ CU6 } & $\begin{array}{l}0.4184 \\
0.4801 \\
0.4576 \\
0.4194\end{array}$ & \multirow[t]{2}{*}{0.8598} \\
\hline & 0.4385 & & & 0.4574 & \\
\hline CU4j & $\begin{array}{l}0.6150 \\
0.6554\end{array}$ & 0.6800 & \multirow{3}{*}{ CU7 } & $\begin{array}{l}0.4043 \\
0.4262\end{array}$ & \multirow{3}{*}{0.8742} \\
\hline \multirow[t]{3}{*}{ CU4i } & $\begin{array}{l}0.4205 \\
0.6255 \\
0.6572\end{array}$ & 0.6970 & & $\begin{array}{l}0.4151 \\
0.4184 \\
0.3755\end{array}$ & \\
\hline & & & & 0.4081 & \\
\hline & & & CU8 & $\begin{array}{l}0.4920 \\
0.5129 \\
0.4970 \\
0.4979\end{array}$ & 0.8868 \\
\hline
\end{tabular}

Table 5 shows the correlation matrix between the CUs and also reports Cronbach's alpha. Almost all these latter values are close to or above 0.6, indicating an acceptable fit in terms of reliability [45]. On the other hand, the values of the coefficients of the Pearson correlations are relatively low (and significant at a level of 5\%), thus confirming that the research model is free of multi-collinearity.

Table 5. Correlation matrix of the competency units.

\begin{tabular}{cccccccccc}
\hline & CU1 & CU2 & CU3 & CU4_j & CU4_i & CU5_v & CU5_g & CU6 & CU7 \\
\hline CU2 & 0.6124 & - & & & & & & & \\
CU3 & 0.5669 & 0.5748 & - & & & & & & \\
CU4_j & 0.4081 & 0.4738 & 0.4417 & - & & & & & \\
CU4_i & 0.2617 & 0.2906 & 0.3155 & 0.2494 & - & & & & \\
CU5_v & 0.3654 & 0.4278 & 0.4276 & 0.3725 & 0.6236 & - & & & \\
CU5_g & 0.4638 & 0.4467 & 0.5620 & 0.3475 & 0.4642 & 0.7526 & - & & \\
CU6 & 0.5688 & 0.6142 & 0.6770 & 0.4741 & 0.4907 & 0.7179 & 0.7837 & - & \\
CU7 & 0.5065 & 0.5673 & 0.5937 & 0.4372 & 0.5352 & 0.7376 & 0.7836 & 0.8237 & - \\
CU8 & 0.3794 & 0.3565 & 0.4033 & 0.3657 & 0.4650 & 0.6824 & 0.5404 & 0.5909 & 0.6987 \\
\hline
\end{tabular}


In a second stage we calculated the skill gap; that is, what students are expected to have learnt on completion of their studies and their current level of proficiency of each of the CUs. This gap can be expressed in Equation (1):

$$
C U_{i} \text { Gap }=100 \times \frac{4-\overline{C U}_{i}}{3}
$$

where $C U_{i}$ Gap denotes the skill gap in the competency unit $i . \overline{C U}_{i}$. is the average value of the items included in $C U_{i}$ and 3 refers to the distance between the maximum level of acquisition in our Likert scale (4) as well as the minimum value (1). This skill gap will reveal the real need in sustainable training and can be useful in assisting the identification of the CUs in sustainability that should be emphasized at university level. We report the results of this analysis (see Section 4.1) for the whole sample, and discriminating by the control variables: gender, studies and training. Lastly, in the third stage (see Section 4.2), a series of two-way ANOVA analyses were run to investigate the association between the control variables and the level of acquisition of the sustainability CUs.

\section{Results}

\subsection{Skill Gap in Sustainability CUs}

Table 6 shows the main descriptive (minimum and maximum value, standard deviation and mean) of each competency unit on sustainability. As may be inferred from the mean values presented, it seems that, on average, students have little knowledge about them, as predominant responses ranged between 1 (nothing) and 2 (little). The CUs in which students scored lower are those related to ethical and deontological aspects (CU8) linked to their field of activity, and the methods and tools to estimate the economic viability of a project (CU5_v) with a skill gap of 51\% and 52\%, respectively. The highest skill gap is found in CU4, which refers to social impact indicators (the two sub-dimensions), where the gap is above $60 \%$.

Table 6. Descriptives of the CUs on sustainability and the skill gap.

\begin{tabular}{ccccccccccc}
\hline & CU1 & CU2 & CU3 & CU4_j & CU4_i & CU5_v & CU5_g & CU6 & CU7 & CU8 \\
\hline Min & 1 & 1 & 1 & 1 & 1 & 1 & 1 & 1 & 1 & 1 \\
Max & 4 & 3.75 & 3.8 & 4 & 4 & 4 & 4 & 4 & 4 & 4 \\
St. Dev. & 0.61 & 0.55 & 0.56 & 0.66 & 0.65 & 0.68 & 0.69 & 0.64 & 0.66 & 0.73 \\
Mean & 2.27 & 2.36 & 2.33 & 2.12 & 2.00 & 2.44 & 2.31 & 2.30 & 2.26 & 2.48 \\
GAP & $58 \%$ & $55 \%$ & $56 \%$ & $63 \%$ & $67 \%$ & $52 \%$ & $56 \%$ & $57 \%$ & $58 \%$ & $51 \%$ \\
\hline
\end{tabular}

As previously discussed, it might be worth examining if the fields of study (or disciplines) conducive to university play a role in the level of acquisition of sustainability CUs. The descriptive statistics when categorizing the sample by field of study are shown in Table 7. Figure 1 visually illustrates the skill gap of each group individually. Students who have completed a social science high school degree have reported higher scores than those coming from technology, science or other disciplines, thus confirming our initial intuition. The CUs exhibiting the largest differences between groups are: CU4_i (64\% vs. $74 \%)$, CU5_v (51\% vs. $56 \%$ ), CU5_g ( $55 \%$ vs. $60 \%$ ) and CU8 (48\% vs. $59 \%)$. The remaining CUs are quite similar.

We conducted one-way ANOVA tests in order to further investigate the effects of the control variables on the perceived level of achievement of each CU. Looking at this specific variable, there are only two CUs (CU4_i and CU8) in which the means between the two groups are statistically different, suggesting that training in sustainable education at high school is not biased due to the field of study. This means that regardless of the discipline chosen, all students are exposed to equal opportunities to develop sustainable competencies. 
Table 7. Descriptives of the CUs on sustainability and the skill gap by field of study.

\begin{tabular}{cccccccccccc}
\hline Field of Study & Statistic & CU1 & CU2 & CU3 & CU4_j & CU4_i & CU5_v & CU5_g & CU6 & CU7 & CU8 \\
\hline \multirow{4}{*}{ Social sciences } & Min & 1 & 1 & 1 & 1 & 1 & 1 & 1 & 1 & 1 \\
and & Max & 4 & 3.75 & 3.8 & 4 & 4 & 4 & 4 & 4 & 4 & 4 \\
humanities & St. Dev. & 0.63 & 0.55 & 0.59 & 0.66 & 0.65 & 0.71 & 0.71 & 0.65 & 0.65 & 0.73 \\
& Mean & 2.29 & 2.36 & 2.35 & 2.13 & 2.07 & 2.48 & 2.35 & 2.30 & 2.28 & 2.56 \\
& GAP & $57 \%$ & $55 \%$ & $55 \%$ & $62 \%$ & $64 \%$ & $51 \%$ & $55 \%$ & $57 \%$ & $57 \%$ & $48 \%$ \\
\hline \multirow{5}{*}{ Other } & Min & 1 & 1.25 & 1.4 & 1 & 1 & 1 & 1 & 1 & 1 & 1 \\
& Max & 3.67 & 3.50 & 3.40 & 4.00 & 3.00 & 3.33 & 3.50 & 3.40 & 3.67 & 3.75 \\
& St. Dev. & 0.56 & 0.55 & 0.47 & 0.68 & 0.60 & 0.59 & 0.62 & 0.60 & 0.69 & 0.69 \\
& Mean & 2.22 & 2.37 & 2.29 & 2.09 & 1.78 & 2.32 & 2.20 & 2.28 & 2.20 & 2.24 \\
\multirow{2}{*}{ ANOVA } & GAP & $59 \%$ & $55 \%$ & $57 \%$ & $64 \%$ & $74 \%$ & $56 \%$ & $60 \%$ & $57 \%$ & $60 \%$ & $59 \%$ \\
\hline & Z & -0.457 & 0.029 & -0.520 & -0.283 & $-\mathbf{2 . 3 7 9}$ & -0.348 & -0.568 & 1.458 & 1.154 & $\mathbf{- 2 . 1 5 5}$ \\
& Prob (z) & 0.6480 & 0.9772 & 0.6032 & 0.7774 & $\mathbf{0 . 0 1 7 4}$ & 0.7276 & 0.5702 & 0.1450 & 0.2483 & $\mathbf{0 . 0 3 0 7}$ \\
\hline
\end{tabular}

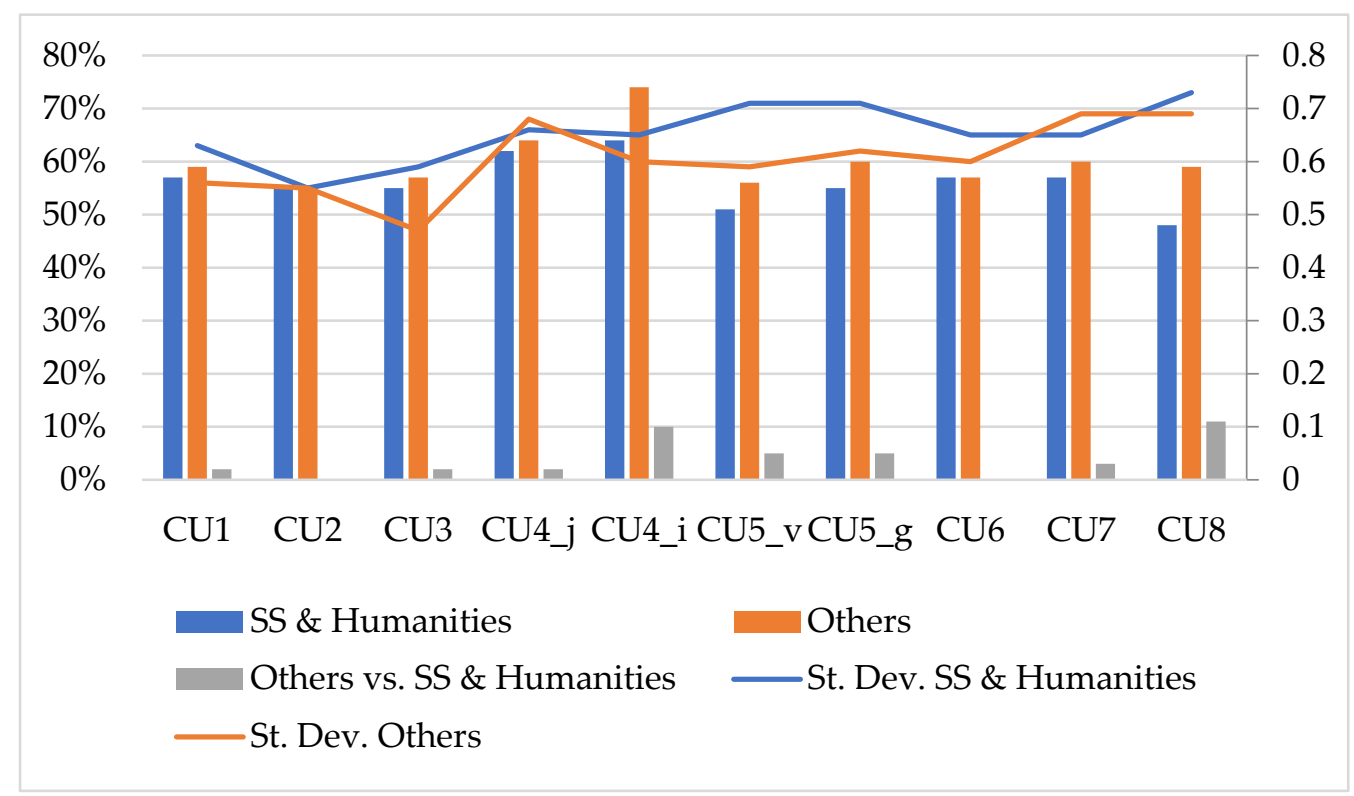

Figure 1. Comparison of the skill gap by field of study.

Another factor that could account for why some students have a more solid acquisition of the CUs is if they have received training in sustainability, either formal or informal, prior to university. As observed in Table 8 and Figure 2, this variable is the one showing the greatest differences (when comparing the two subsamples by university). When splitting the total sample by this variable, the results verify its relevance. Indeed, as confirmed by the ANOVA, the differences are quite striking when comparing the level of acquisition of sustainable competencies between students who had received education on sustainabilityrelated issues and then those that had not. The average values for all CUs, except for CU4 (the two sub-dimensions), are statistically significant. In some CUs, the differences in the skill gap reach 16 percentage points (CU1 and CU2). Other competencies such as CU5_g, CU6, CU7 also present important differences. This result is not surprising, since students who have in one way or another received or been exposed to sustainable training already possess (to a greater or lesser extent) some sustainability CUs. 
Table 8. Descriptives of the CUs on sustainability and the skill gap by prior training in sustainability.

\begin{tabular}{|c|c|c|c|c|c|c|c|c|c|c|c|}
\hline $\begin{array}{c}\text { Prior } \\
\text { Training }\end{array}$ & Statistic & CU1 & CU2 & CU3 & CU4_j & CU4_i & CU5_v & CU5_g & CU6 & CU7 & CU8 \\
\hline \multirow{5}{*}{ Yes } & Min & 1.33 & 1.50 & 1.60 & 1.00 & 1.00 & 1.00 & 1.00 & 1.00 & 1.00 & 1.00 \\
\hline & Max & 3.67 & 3.75 & 3.60 & 4.00 & 3.33 & 4.00 & 4.00 & 4.00 & 4.00 & 4.00 \\
\hline & St. Dev. & 0.58 & 0.45 & 0.44 & 0.65 & 0.68 & 0.72 & 0.66 & 0.59 & 0.67 & 0.75 \\
\hline & Mean & 2.49 & 2.62 & 2.47 & 2.20 & 2.02 & 2.50 & 2.45 & 2.48 & 2.44 & 2.54 \\
\hline & GAP & $50 \%$ & $46 \%$ & $51 \%$ & $60 \%$ & $66 \%$ & $50 \%$ & $52 \%$ & $51 \%$ & $52 \%$ & $49 \%$ \\
\hline \multirow{5}{*}{ No } & Min & 1 & 1 & 1 & 1 & 1 & 1 & 1 & 1 & 1,17 & 1 \\
\hline & Max & 4.00 & 3.50 & 3.80 & 4.00 & 4.00 & 4.00 & 4.00 & 4.00 & 4.00 & 4.00 \\
\hline & St. Dev. & 0.55 & 0.51 & 0.63 & 0.64 & 0.64 & 0.63 & 0.59 & 0.63 & 0.64 & 0.74 \\
\hline & Mean & 2.02 & 2.13 & 2.16 & 1.96 & 2.00 & 2.30 & 2.01 & 2.08 & 2.04 & 2.37 \\
\hline & GAP & $66 \%$ & $62 \%$ & $61 \%$ & $68 \%$ & $67 \%$ & $57 \%$ & $66 \%$ & $64 \%$ & $65 \%$ & $54 \%$ \\
\hline \multirow{2}{*}{ ANOVA } & Z & -3.388 & -4.315 & -3.153 & -1.506 & 0.739 & -2.756 & -2.019 & -3.288 & -0.3115 & -2.689 \\
\hline & Prob (z) & 0.0007 & 0.0000 & 0.0016 & 0.1321 & 0.4599 & 0.0002 & 0.0435 & 0.0010 & 0.0018 & 0.0044 \\
\hline
\end{tabular}

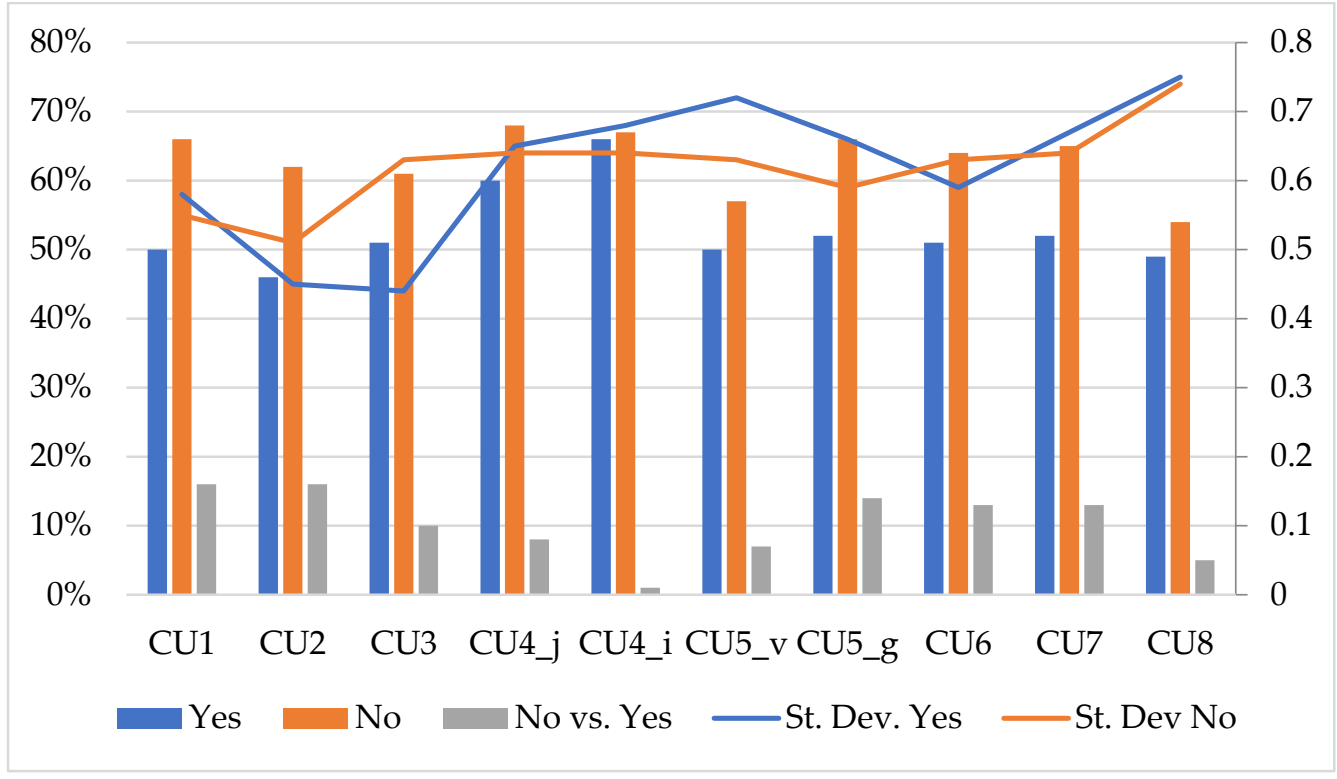

Figure 2. Comparison of the skill gap differentiating by prior training.

Finally, the literature points to gender differences in the way students learn. To test whether this trend is also valid in our setting, we examined for potential differences in the current level of knowledge of CUs due to gender (see Table 9 and Figure 3). The results of this examination reveal an interesting scenario. In 6 out of the 10 CUs (CU1, CU2, CU3, CU6, CU7 and CU8) women score higher than men. On the other hand, men are only in an advantageous position when it comes to assessing the social impact (men have a lower skill gap in both CU4_j and CU4_i), although the average scores are quite similar. No relevant variations due to gender are found in the other CUs (CU5_v and CU5_g). The ANOVA analyses validate the hypothesis that women have a statistically significant lower skill gap, although this statement only holds true for three CUs: general knowledge (CU1), interaction with other actors in the field of profession (CU7) and deontological and ethical principles (CU8). 
Table 9. Descriptives of the CUs on sustainability and the skill gap by gender.

\begin{tabular}{cccccccccccc}
\hline Gender. & Statistic & CU1 & CU2 & CU3 & CU4_j & CU4_i & CU5_v & CU5_g & CU6 & CU7 & CU8 \\
\hline \multirow{6}{*}{ Men } & Min & 1 & 1.25 & 1 & 1 & 1 & 1 & 1 & 1 & 1 & 1 \\
& Max & 3.33 & 3.50 & 3.60 & 4.00 & 4.00 & 4.00 & 3.75 & 3.60 & 3.67 & 4.00 \\
& St. Dev. & 0.51 & 0.50 & 0.51 & 0.61 & 0.62 & 0.68 & 0.62 & 0.56 & 0.63 & 0.69 \\
& Mean & 2.20 & 2.35 & 2.32 & 2.15 & 2.03 & 2.45 & 2.31 & 2.29 & 2.21 & 2.45 \\
& GAP & $60 \%$ & $55 \%$ & $56 \%$ & $62 \%$ & $66 \%$ & $52 \%$ & $56 \%$ & $57 \%$ & $60 \%$ & $52 \%$ \\
\hline \multirow{6}{*}{ Women } & Min & 1 & 1 & 1 & 1 & 1 & 1 & 1 & 1 & 1 & 1 \\
& Max & 4.00 & 3.75 & 3.80 & 4.00 & 3.33 & 4.00 & 4.00 & 4.00 & 4.00 & 4.00 \\
& St. Dev. & 0.71 & 0.61 & 0.62 & 0.72 & 0.68 & 0.68 & 0.78 & 0.72 & 0.69 & 0.77 \\
& Mean & 2.36 & 2.38 & 2.35 & 2.08 & 1.95 & 2.43 & 2.33 & 2.31 & 2.31 & 2.51 \\
& GAP & $55 \%$ & $54 \%$ & $55 \%$ & $64 \%$ & $68 \%$ & $52 \%$ & $56 \%$ & $56 \%$ & $56 \%$ & $50 \%$ \\
\hline \multirow{2}{*}{ ANOVA } & Z & 0.776 & 2.232 & 0.153 & 0.360 & 0.438 & 0.042 & 0.031 & 0.039 & 0.730 & 0.642 \\
& Prob (z) & 0.008 & 0.1378 & 0.7002 & 0.5519 & 0.503 & 0.8406 & 0.8663 & 0.8740 & 0.0393 & 0.021 \\
\hline
\end{tabular}

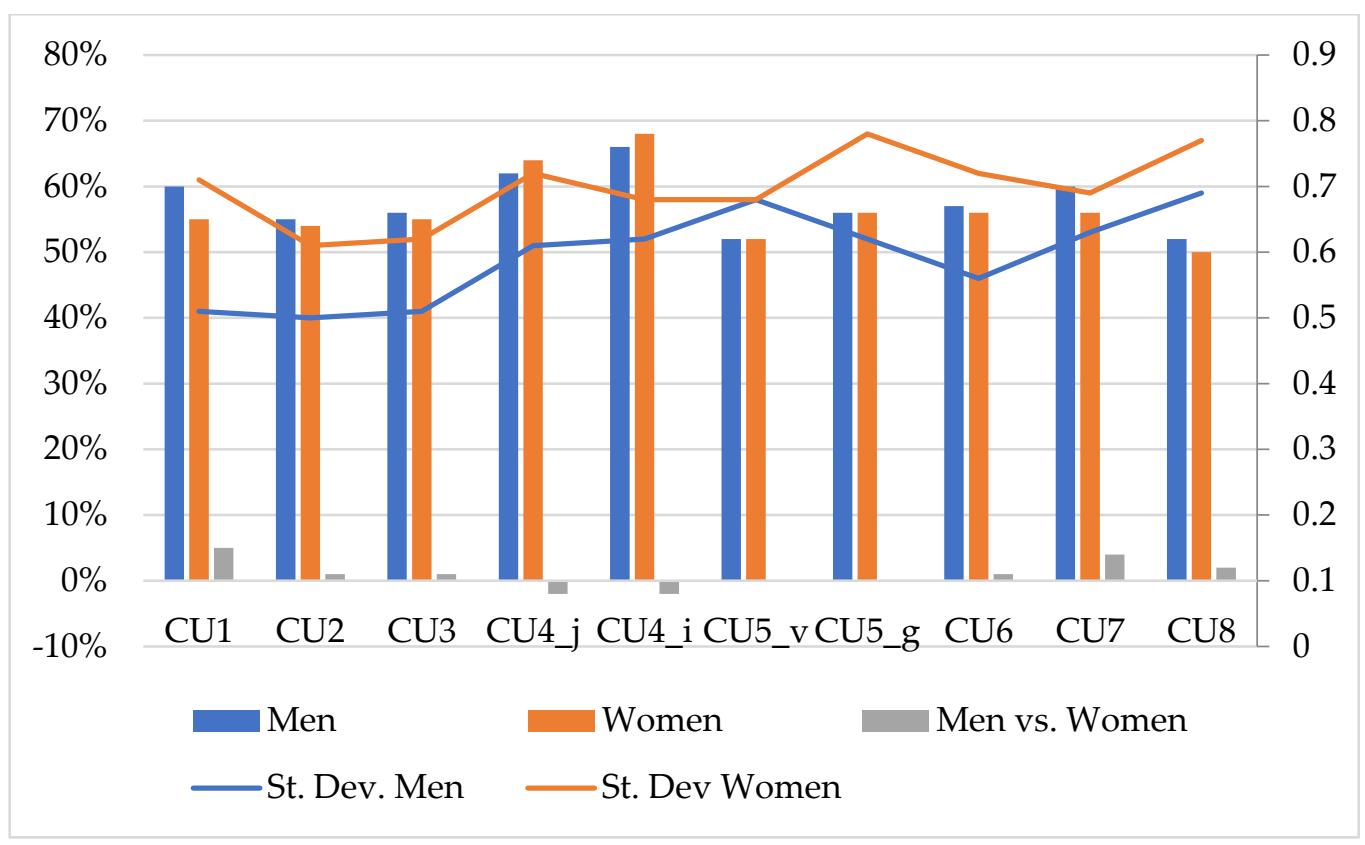

Figure 3. Comparison of the skill gap differentiating by gender.

\subsection{Two-Way ANOVA}

To investigate the existence of a relation between the control variables, a multivariate analysis of the variables (two-way ANOVA) was conducted, considering each of the CUs as the dependent variables (each CU was tested in an individual fashion in separate models) and studies, training and gender as the independent ones.

The results show that female students who have received previous training in sustainability are more likely to have developed higher CUs, particularly CU1 $(\mathrm{F}=6.52)$, CU2 $(\mathrm{F}=1.05), \mathrm{CU} 3(\mathrm{~F}=1.19), \mathrm{CU} 5$ g $(\mathrm{F}=0.12), \mathrm{CU} 6(\mathrm{~F}=0.44)$ and CU7 $(\mathrm{F}=0.66)$, all significant at $p$-value $\leq 0.01$. This model yielded adequate values in the test for multivariate significance $(p>0.05)$, thereby enabling us to reject the null hypothesis.

The model in which we compared the studies and training variables also reported some interesting insights. In this case, students with a background in humanities or social science (at high school), and who in addition have received some sort of training in sustainability, are also more likely to have developed some specific CUs: CU3 $(\mathrm{F}=7.32, p$-value $=0.01)$, $\mathrm{CU} 4 \_\mathrm{i}(\mathrm{F}=5.25, p$-value $=0.02), \mathrm{CU} 5 \_\mathrm{g}(\mathrm{F}=8.54, p$-value $=0.00)$ and CU7 $(\mathrm{F}=3.74, p$-value $=0.04)$. In this analysis, the multivariate values also present significance $(p$-value $>0.05)$, allowing us again to reject the null hypothesis. 
In the case of the last multivariate analysis we undertook, gender contrasted with studies, and non-significant differences were found.

\section{Discussion and Conclusions}

Unsupportive hyper-consumption, production systems that are not respectful of the environment, and the demographic explosion, prevent the needs of the majority of the world's population from being satisfied, which translates into unsustainable imbalances.

Given that today's students will in the future be responsible for making individual decisions about consumption and production, and some of whom might even influence collective decisions, it is very important to include the principles of sustainability in higher education, regardless of the field of expertise. The design of learning strategies with this focus is of paramount importance for generating sustainable awareness among students, and for changing their attitudes towards behaviours that are more respectful to society and the environment. An appropriate educational training in sustainability competencies would facilitate this change, and thus be more in alignment with contributing further to the sustainable development goals.

The arguments outlined above explain why research on the field of education for sustainable development at higher education levels is increasingly drawing the attention of both academics and policy makers. While many different initiatives already exist, more research is required to develop new tools and strategies; first, to evaluate the level of proficiency of sustainability competencies possessed by students, and second, based on the results of this assessment, to design and incorporate interventions for correcting the potential imbalances identified [8].

This work builds on the map of sustainability competencies [11,42] and particularises it for business and management students. Taking as a starting point the list of competencies included in the map-those that students should have acquired on completing their studies-we have designed an instrument that facilitates this competency assessment. This instrument takes the form of a questionnaire that can be adapted to other disciplines and provides a useful tool for business faculties and schools to determine the level of proficiency in sustainability competencies possessed by freshmen. Based on the results, more informative decisions can be made about how to direct teaching strategies in specific directions in order to address those competencies that are less developed.

For the purpose of this study, we submitted the questionnaire to a group of first-year students enrolled in the Bachelor's Degree in Business Administration and Management at two Spanish universities (UIC and UM) during the academic year 2020/21. This survey provides valuable information on the self-perceived level of acquisition of competency units that appear on the competency map. In addition to a description of how the questionnaire has been designed and validated, we also exemplify how it can be applied and the type of analysis that can be derived from its application, reporting the assessment of sustainability competencies of this particular group of students. We discuss not only the level of achievement of the different units of competencies, but also explore the skill gap in greater depth; that is, the difference between the expected level of proficiency students should possess when graduating and the current level of expertise. The instrument thus provides a snapshot of the reality of a given group of students and, based on this information, the teaching staff may be able to design an educational strategy aimed at improving the level of acquisition of those competency units. Following this line of research, some studies have already started investigating the potential links between different pedagogical strategies and the development of competencies in sustainability [46-48].

Our findings reveal that students perceive that they have deficiencies, since they present a skill gap in the units of competency that oscillates between $51 \%$ (CU8) and $67 \%$ (CU4_i). The unit of competencies with the highest GAP refers to aspects concerning social justice and social impact-CU4_i $(\mathrm{GAP}=67 \%)$ and $\mathrm{CU} 4 \_\mathrm{j}(\mathrm{GAP}=63 \%)$-as well as interactions with other actors (CU7, GAP $=58 \%$ ) and general knowledge (CU1, GAP $=58 \%$ ). A possible interpretation could be that, since they have yet to study specific business- 
related subjects (e.g., microeconomics, world economics, macroeconomics, business ethics, finance, etc.), first-year students are unaware of the indicators for measuring the social impact of their professional decisions (products and services), and have only a vague idea of what their future professional life might be. Business studies are very broad in scope, so this uncertainty about the type of employment they might pursue is perfectly understandable. Thus, in order to address these deficiencies and foster the acquisition of sustainable competencies, educational interventions at university level should be aimed at presenting students with real case studies in which they are faced with problems requiring different solutions, taking into account their potential impact. Such types of activity, based on problem- or challenge-based learning, mimic real life situations and are intended to help students become aware of the implications underlying their decisions.

A further relevant finding is that students with a background (high school) in social sciences and humanities appear to behave no differently from those coming from other disciplines. The small variations found between the two groups indicate that, while in high schools students receive a different preparation (more oriented towards specific career paths such as technology, social sciences, sciences, arts, etc.), the type of competencies addressed are not dependent on the content taught. Increasingly, teaching methods are including experiential activities such as dealing with real problems or simulation of real cases. In doing so, students are faced with decisions where sustainable principles enter into play, and therefore CUs can be introduced to a greater or lesser extent. Significant differences between the two groups are only found when examining the specific indicators for measuring and describing the social impact (CU4i), and the deontological and ethical principles of the profession and of sustainability (CU8). It may therefore be concluded that the introductory courses in economics undertaken at high school seem to play a role, at least in regard to providing an initial understanding and/or awareness on the fundamentals of how to describe and measure the social impact of products and services related to their professional field, and the ethical implications of the different activities undertaken. However, it should be pointed out that the skill gap is high, which indicates that university professors should devote special attention to this issue in the courses they teach. How to measure social impact is something that stretches across all departments of an organisation (e.g., sales, operations, human resources, accounting, etc.), so these sustainable CUs can be encouraged regardless of the specific focus of the course.

As expected, our findings also reveal that prior training in sustainability is highly influential, since significant differences are found when splitting the sample by taking this variable into account. Students with a prior background in sustainability outperform those who do not (higher average values in all CUs). The presence of students with and without prior knowledge in sustainability in the same classroom poses a considerable challenge to educators, since they run the risk of taking for granted concepts that not all students have acquired and therefore overlook basic concepts. On the other hand, they may address a given topic only superficially, in which case students with a more extensive knowledge of the subject may get bored. One way of minimizing this problem could consist in applying a strategy requiring students to collaborate with each other in order to solve a problem or an exercise. For instance, students could be grouped according to a series of parameters (e.g., knowledge of sustainability, ability to work in teams, entrepreneurial behaviour, etc.), thus forming teams with heterogeneous profiles in which each student is unique and all profiles are needed to solve the task. This strategy could be combined with the introduction of features coming from gamification [49].

Finally, we also investigated the potential effect of gender. As discussed in the literature review, women tend to develop a more sensitive attitude towards sustainability. Nevertheless, our results suggest that the differences are minimal, and are only statistically significant (in favour of women) when considering general knowledge (CU1) and the choice of sustainability strategies, products and services related to their professional field (CU6). Some activities could be implemented to reduce these differences, as follows: First, as discussed above, it is highly advisable to have students work in mixed groups. It is not 
necessary for the professor to decide on the formation of such groups, but rather to establish gender diversity as a prerequisite for choosing group members. Second, additional effort should made to raising awareness among male students about the importance of sustainability. This can be done by organizing talks, workshops and seminars that are led by men. In this way, male students could feel more identified with and committed to an important issue such as sustainability. Finally, specific activities could be organized to provide students with first-hand experiences designed to sensitize them about the relevance of sustainability. If properly managed, such activities and experiences would help male students understand that this is an area in which men also have a place, and where they can lead projects that have an impact on society.

The two-dimensional ANOVA analyses reinforce the all the foregoing. Women with previous training in sustainability show a greater likelihood of attaining high levels in certain competencies (CU1, CU2, CU3, CU5_g, CU6 and CU7) concerning the dimensions of sustainability, environmental impact, resource planning in projects and interaction with other social agents. Furthermore, those students with an educational background in social sciences and a humanities profile, and who have received some training in sustainability, are more likely to acquire a high level of proficiency in certain units of competency (CU3, CU4_i, CU5_g and CU7).

In the light of the above findings, a series of implications can be derived. First, we believe that this study makes an original and necessary contribution to the higher education and sustainability literature by proposing an instrument that is easy to implement and capable of creating a map indicating the deficiencies that students may present when entering university. This information is critical for the effective design of educational intervention strategies. Moreover, the consistent use of this instrument at the beginning of each academic year would enable students' progress to be monitored and therefore to revise the teaching strategies programmed accordingly. Second, we argue that is necessary to increase the use of interactive and action-oriented methodologies, such as project-based learning, service learning, problem-based learning, case studies, discussion groups and roleplaying games. All these methodologies share the common feature of promoting analysis and critical thinking, with the aim of finding innovative solutions to social problems, which in turn promote the development of non-cognitive skills to help students in the development of sustainability competencies. Third, the above methodologies should be applied in a multidisciplinary way involving several subjects. At this stage, both horizontal and vertical coordination are of paramount importance. Specifically, the establishment of good coordination mechanisms would prevent the overlapping of topics (or even case studies) between subjects and thus allow the distribution of the competencies among the curricula. This entails decisions about which competency units should be emphasized and to what extent-the level of depth-in each course. In addition, professors could reach agreements about the most appropriate teaching strategies to adopt at each educational level. Likewise, coordination might also open the door to the development of joint activities between subjects and (even) among students from different courses, thereby fostering interdisciplinary collaboration. Fourth, not all professors possess the knowledge and ability for the successful introduction of these methodologies in their courses. In addition, specific training in sustainability is necessary for professors themselves. In order to remedy these limitations, the design of a teacher training programme aimed at providing this information is regarded as necessary, enabling teaching staff to learn how to introduce these methodologies in their day-to-day teaching tasks. Last but not least, it is advisable to develop educational policy actions that bring together universities and high schools, with the ultimate goal of coordinating the inclusion of sustainability competencies in the curriculum of secondary and tertiary education.

Future studies should consider expanding the sample and replicating the study at other universities with business degrees in order to determine whether the results are consistent across different institutions. A further avenue that merits exploration is the effect of the sociocultural environment on students. Furthermore, family values and behaviours 
might also influence and shape students' sustainability competencies. In this regard, we observed that students from the UIC (located in the region of Catalonia) have on average a higher level of acquisition of sustainable CUs than those enrolled at the UM (in the Spanish region of Murcia). It is likely that the educational system in both regions accounts for these differences. Unfortunately, our questionnaire did not cover these types of factors, so future studies should take them into account and ask respondents to provide such information when filling in the survey. On a related note, another promising research line could focus on the type of prior training received; for instance, it would be interesting to determine where students may have developed their sustainable awareness-whether in school or in extracurricula activities, events, etc.-and what prompted students to engage in such activities. Finally, while we have followed a rigorous process in the collection of data, the items used to measure the extent to which each competency unit is developed is based on self-perception metrics. We acknowledge the difficulty in establishing objective measures for evaluating the level of acquisition of a given skill and the biases related to the use of self-assessment surveys. The scales used in this study were validated and showed sufficient internal consistency, although future research work could be devoted to the investigation of alternative metrics to assess at what point and to what extent they have acquired such competencies.

Author Contributions: Conceptualization, A.M. and J.B.-M.; methodology and analysis, A.M.; validation, J.B.-M.; data collection, J.-V.L.-C. and A.M.; literature review, U.F.-M. and J.-V.L.-C.; writing—original draft preparation, A.M., U..F.-M. and J.-V.L.-C.; writing—review and editing, J.B.-M. All authors have read and agreed to the published version of the manuscript.

Funding: This work was supported by the Spanish Ministerio de Economía y Competitividad, from study design to submission, under grant number EDU2015-65574-R; by the Spanish Ministerio de Ciencia, Innovación y Universidades, the Spanish Agencia Estatal de Investigación (AEI), and the Fondo Europeo de Desarrollo Regional (FEDER), from study design to submission, under grant number RTI2018-094982-B-I00.

Institutional Review Board Statement: Not applicable.

Informed Consent Statement: Not applicable.

Data Availability Statement: Not applicable.

Acknowledgments: The authors are grateful for the support of the other members of the EDINSOST2 project in which this study is framed. We also would like to thank the pool of experts that helped us in the validation of the questionnaire and to all the students who answered it.

Conflicts of Interest: The authors declare no conflict of interest.

\section{References}

1. Turney, C.; Ausseil, A.-G.; Broadhurst, L. Urgent need for an integrated policy framework for biodiversity loss and climate change. Nat. Ecol. Evol. 2020, 4, 996. [CrossRef]

2. IPBES. Summary for Policymakers of the Global Assessment Report on Biodiversity and Ecosystem Services of the Intergovernmental Science-Policy Platform on Biodiversity and Ecosystem Services; Brondizio, E.S., Settele, J., Díaz, S., Ngo, H.T., Eds.; IPBES Secretariat: Bonn, Germany, 2020; 1148p. [CrossRef]

3. WWF. Nature-Based Solutions for Climate Change. WWF Brief. July 2020. Available online: https://wwfint.awsassets.panda. org/downloads/wwf_nature_based_solutions_for_climate_change__july_2020_final.pdf (accessed on 20 July 2021).

4. Vilches, A.; Pérez, D.G. Emergencia planetaria: Necesidad de un planteamiento global. Educ. Siglo XXI 2007, 25, 19-49.

5. Aznar-Minguet, P.; Ull, M.A.; Martínez-Agut, M.P.; Piñero, A. Evaluar para transformar: Evaluación de la docencia universitaria bajo el prisma de la sostenibilidad. Enseñanza Cienc. 2017, 35, 5-27.

6. OECD. OECD Skills Strategy Diagnostic Report: Mexico; OECD Publishing: París, Francia, 2017.

7. Echeverría, B.; Martínez, P. Revolución 4.0, competencias, educación y orientación. Rev. Digit. Investig. Docencia Univ. 2017, 12, 4-34. [CrossRef]

8. Cebrián, G.; Junyent, M.; Mula, I. Competencies in education for sustainable Development: Emerging teaching and research developments. Sustainability 2020, 12, 579. [CrossRef]

9. Pizzutilo, F; Venezia, E. On the maturity of social responsibility and sustainability integration in higher education institutions: Descriptive criteria and conceptual framework. Int. J. Manag. Educ. 2021, 19, 100515. [CrossRef] 
10. Neamțu, D.M.; Bejinaru, R.; Hapenciuc, C.V.; Condratov, C.; Stanciu, P. Analysis and modelling of influence factors in the configuration of a sustainable university. Case study: "Ștefan cel Mare" University of Suceava. Amfiteatru Econ. 2020, 22, 391-410. [CrossRef]

11. Segalàs-Coral, J.; Sánchez Carracedo, F. El proyecto EDINSOST. Formación en las Universidades españolas de profesionales como agentes de cambio para afrontar los retos de la sociedad. Rev. Educ. Ambient. Sostenibilidad 2019, 1, 1204. [CrossRef]

12. Ricaurte, P. Pedagogies for the open knowledge society. Int. J. Educ. Technol. High. Educ. 2016, 13. [CrossRef]

13. Aliaga-Pacora, A.A.; Luna-Nemecio, J. La construcción de competencias investigativas del docente de posgrado para lograr el desarrollo social sostenible. Espacios 2020, 41, 1-12.

14. United Nations. Agenda for Sustainable Development. Resolution Adopted by the General Assembly on 25 September 2015 (A/70/L.1). Available online: http:/ / sustainabledevelopment.un.org/post2015/transformingourworld (accessed on 19 July 2021).

15. United Nations. The Sustainable Development Agenda. 2020. Available online: https://www.un.org/sustainabledevelopment/ development-agenda/ (accessed on 20 July 2021).

16. UNESCO. Guía Abreviada de Indicadores de Educación Para el ODS 4. 2018. Available online: http:/ / uis.unesco.org/sites/ default/files/documents / quick-guide-education-indicators-sdg4-2018-sp.pdf (accessed on 20 July 2021).

17. Juárez-Hernández, L.G.; Tobón, S.; Salas-Razo, G.; Carno, A.E.J. Desarrollo sostenible: Educación y sociedad. M+A Rev. Electrónica Medioambiente 2019, 20, 54-72.

18. Andriamihaja, O.R.; Metz, F.; Zaehringer, J.G.; Fischer, M.; Messerli, P. Identifying agents of change for sustainable land governance. Land Use Policy 2021, 100, 104882. [CrossRef]

19. EEA. Growth without Economic Growth. 2021. Available online: https://www.eea.europa.eu/publications/growth-withouteconomic-growth (accessed on 23 July 2021).

20. Ortega-Sánchez, M.A.; Moñino, R.J.; Bergillos, P.; Magaña, M.; Clavero, M.; Díez-Manguito, A.; Baquerizo, A. Confronting learning challenges in the field of maritime and coastal engineering: Towards an educational methodology for sustainable development. J. Clean. Prod. 2021, 171, 733-742. [CrossRef]

21. Jim, Y.C.; Shen, J.P. Higher education for sustainable development: A systematic review. Int. J. Sustain. High Educ. 2016, 17, 633-651. [CrossRef]

22. UNESCO. Education for Sustainable Development Goals: Learning Objectives. 2017. Available online: https:/ / unesdoc.unesco. org/ark:/48223/pf0000247444 (accessed on 20 July 2021).

23. García-Valdés, M.G.; Juárez-Hernández, L.G. Diseño y validación de un instrumento para evaluar la formación en sostenibilidad en estudiantes de educación superior. IE Rev. Investig. Educ. Rediech 2019, 10, 37-54. [CrossRef]

24. SDSN. Accelerating Education for the SDGs in Universities: A Guide for Universities, Colleges, and Tertiary and Higher Education Institutions; Sustainable Development Solutions Network: New York, NY, USA, 2020; Available online: https:/ / www.unsdsn. org/accelerating-education-for-the-sdgs-in-univerisities (accessed on 19 July 2021).

25. CRUE. La Universidad Española en Cifras; Dir. Juan Hernández Armenteros and José Antonio Pérez García; CRUE, 2019; Available online: https:/ / www.crue.org/wp-content/uploads/2020/02/Resumen-Ejecutivo-CRUE-2019_DIGITAL.pdf (accessed on 18 June 2021).

26. European Commission. Communication from the Commission to the European Parliament, the Council, the European Economic and Social Committee of the Regions - Closing the Loop_An EU Action Plan for the Circular Economy; COM/2015/0614 Final; European Commission: Brussels, Belgium, 2015.

27. Morseletto, P. Targets for a circular economy. Resour. Conserv. Recycl. 2020, 153, 104553. [CrossRef]

28. Mendoza, C.A.S. Visiones del Desarrollo Sostenible; Ediciones de la U: Bogotá, Colombia, 2021.

29. Michalos, A.C.; Creech, H.; McDonald, C.; Kahlke, P.M. Knowledge, Attitudes and Behaviours. Concerning Education for Sustainable Development: Two Exploratory Studies. Soc. Indic. Res. 2011, 100, 391-413. [CrossRef]

30. Michalos, A.C.; Creech, H.; Swayze, N. Measuring Knowledge, Attitudes and Behaviours Concerning Sustainable Development among Tenth Grade Students in Manitoba. Soc. Indic. Res. 2012, 106, 213-238. [CrossRef]

31. Olsson, D.; Gericke, N.; Chang Rundgren, S.-N. The effect of implementation of education for sustainable development in Swedish compulsory schools-Assessing pupils' sustainability consciousness. Environ. Educ. Res. 2015, 22, 176-202. [CrossRef]

32. Boeve-de Pauw, J.; Gerikle, N.; Olsson, D.; Berglund, T. The Effectiveness of Education for Sustainable Development. Sustain. Sci. 2015, 7, 15693-15717. [CrossRef]

33. Suárez-López, R.; Eugenio-Gozalbo, M. How is sustainability addressed in primary and secondary education curricula? Assessing the cases of Spain and Portugal. Int. Res. Geogr. Environ. Educ. 2021. [CrossRef]

34. Cardeñoso, J.M.; Azácate, P.; Oliva, J.M. La sostenibilidad en la formación inicial del profesorado de Secundaria: Incidencia en los estudiantes de Ciencias y Matemáticas. Rev. Eureka Sobre Enseñanza Divulg. Cienc. 2013, 10, 780-796. [CrossRef]

35. Pozo, M.; Toala, J.; Quiñonez, M. La familia y su influencia en el comportamiento de los niños en el aula. In Memorias del Cuarto Congreso Internacional de Ciencias Pedagógicas de Ecuador: La Formación y Superación Del Docente: "Desafíos Para El Cambio de La Educación"; En el Siglo XXI, 2018; Volume 1, pp. 1012-1021. ISBN 978-9942-17-033-0. Available online: https: / / dialnet.unirioja.es/servlet/articulo?codigo=7220627 (accessed on 20 July 2021).

36. Zheng, X.; Wang, R.; Hoekstra, A.Y.; Krol, M.S.; Zhang, Y.; Guo, K.; Sanwal, M.; Sun, Z.; Zhu, J.; Zhang, J.; et al. Consideration of culture is vital if we are to achieve the Sustainable Development Goals. One Earth 2021, 4, 307-319. [CrossRef] 
37. Pearson, A.R.; Ballew, M.T.; Naiman, S.; Schuldt, J.P. Race, class, gender and climate change communication. Sustain. Clim. Chang. 2017. [CrossRef]

38. Xiao, C.; McCright, A.M. Explaining Gender Differences in Concern about Environmental Problems in the United States. Soc. Nat. Resour. 2010, 25, 1067-1084. [CrossRef]

39. Sánchez-Carracedo, F.; Sureda, B.; Moreno-Pino, F.M.; Romero-Portillo, D. Education for Sustainable Development in Spanish engineering degrees. Case study. J. Clean. Prod. 2021, 294, 126322. [CrossRef]

40. Valderrama-Hernandez, R.; Alcantara Rubio, L.; Sanchez-Carracedo, F.; Caballero, D.; Serrate, S.; Gil-Domenech, D.; VidalRamentol, S.; Minano, R. Does the Spanish university system teach sustainability? Perception of the students of four universities. Educ. XX1 2020, 23, 221-245.

41. Sánchez-Carracedo, F.; Moreno-Pino, F.M.; Romero-Portillo, D.; Sureda, B. Education for Sustainable Development in Spanish University Education Degrees. Sustainability 2021, 13, 1467. [CrossRef]

42. Sánchez-Carracedo, F.; Moreno-Pino, F.M.; Sureda, B.; Antúnez, M.; Gutiérrez, I. A Methodology to Analyze the Presence of Sustainability in Engineering Curricula. Case of Study: Ten Spanish Engineering Degree Curricula. Sustain. Sci. 2019, 11, 4553. [CrossRef]

43. Sánchez-Carracedo, F.; López, D.; Bragós, R.; Cabre, J.; Climent, J.; Vidal, E.; Martín, C. Mapping the sustainable development goals into the EDINSOST sustainability map of bachelor engineering degrees. In Proceedings of the 2019 IEEE Frontiers in Education Conference (FIE), Covington, KY, USA, 16-19 October 2019; pp. 1-5.

44. Sánchez Carracedo, F.; Segalàs, J.; Vidal, E.; Martin, C.; Climent, J.; López, D.; Cabré, J. Improving Engineering Educators' Sustainability Competencies by using Competency Maps. The EDINSOST Project. Int. J. Eng. Educ. 2018, 34, 1527-1537.

45. Hair, J.F.; Black, W.C.; Babin, B.J.; Anderson, R.E. Multivariate Data Analysis, 7th ed.; Pearson: Upper Saddle River, NY, USA, 2010.

46. Lozano, R.; Merrill, M.Y.; Sammalisto, K.; Ceulemans, K.; Lozano, F.J. Connecting competences and pedagogical approaches for sustainable development in higher education: A literature review and framework proposal. Sustainability 2017, 9, 1889. [CrossRef]

47. Lozano, R.; Barreiro-Gen, M.; Lozano, F.J.; Sammalisto, K. Teaching sustainability in European higher education institutions: Assessing the connections between competences and pedagogical approaches. Sustainability 2019, 11, 1602. [CrossRef]

48. Cotton, D.; Winter, J. 'It's not just bits of paper and light bulbs': A review of sustainability pedagogies and their potential for use in higher education. In Sustainability Education:Perspectives and Practice across Higher Education; Jones, P., Selby, D., Sterling, S., Eds.; Earthscan: London, UK; New York, NY, USA, 2010; pp. 54-69.

49. Dicheva, D.; Dichev, C.; Agre, G.; Angelova, G. Gamification in education: A systematic mapping study. J. Educ. Technol. Soc. 2015, 18, 75-88. 